\title{
A INSUSTENTÁVEL LEVEZA DO TEMPO: \\ OS OBJETOS DA SOCIEDADE DE CONSUMO EM AULAS DE HISTÓRIA
}

\author{
Francisco Régis Lopes Ramos*
}

\begin{abstract}
RESUMO: $\mathrm{O}$ artigo desenvolve propostas para o uso dos objetos em aulas de história. Argumenta-se que a reflexão sobre as múltiplas relações entre sujeitos e objetos pode ser uma via de acesso para a construção da consciência crítica sobre o tempo, ou melhor, sobre as formas pelas quais acontecem ligações e separações entre passado, presente e futuro. $\mathrm{O}$ intuito é afirmar a necessidade de colocar, a partir do cotidiano vivido e de reflexões sobre a sociedade de consumo, a memória dos objetos no ensino de história.
\end{abstract}

Palavras-chave: Objeto; Ensino de História; Tempo; Sociedade de Consumo

THE UNBEARABLE LIGHTNESS OF TIME:

CONSUMER SOCIETY OBJECTS IN THE HISTORY CLASS

ABSTRACT: This article propose the use of consumer objects in history classes. It argues that the reflection on the multiple relations between citizens and consumer objects may lead to the development of the awareness of time, or better yet, of the connections or disconnections between past, present, and future. The intention is to state the need of a place for the memory of daily life objects and of the reflection on the consumer society in history education.

Keywords: Objects; History Education; Time; Consumer Society

* Doutor em História Social (PUC-SP). Professor do Departamento de História da UFC. E-mail: regisufc@hotmail.com 


\section{VOLUMES DO TEMPO}

Há uma íntima relação entre poder e velocidade. É claro que essa intimidade é historicamente situada, depende das circunstâncias nas quais as sociedades constituem maneiras de compor conexões entre tempo e espaço. Paul Virilio chega a afirmar que, se não é possível fazer separações entre riqueza e velocidade, qualquer estudo sobre o poder passa necessariamente pelo "poder dromocrático". Dromos, em grego, significa corrida. Emerge, portanto, um campo de investigação de primordial importância: a análise sobre a maneira pela qual as sociedades dão suas carreiras e suas paradas. Nesse sentido, Virilio argumenta:

Quer seja nas sociedades antigas através do papel desempenhado pela cavalaria (os primeiros banqueiros romanos eram cavaleiros) ou no poder marítimo através da conquista dos mares, o poder é sempre o poder de controlar um território por mensageiros, por meios de transporte e de transmissão. Independentemente da economia da riqueza, uma abordagem do político não pode ser feita sem uma abordagem da economia da velocidade. O papel desempenhado pela velocidade é diferente segundo a sociedade considerada. A Idade Média conheceu os pombos-correios com Jacques Coeur, o grande financeiro da época. A sociedade colonial conheceu o poder marítimo da Inglaterra e da França. A sociedade do pós-guerra conheceu o poder aéreo com a capacidade dos aviões super-sônicos que transpõem a barreira do som na década de 50. Hoje, a sociedade mundial está em gestação e não pode ser compreendida sem a velocidade da luz, sem as cotações automáticas das bolsas de Wall Street, de Tóquio ou de Londres. (VIRILIO, 2000, p. 15)

Virilio adverte que o ato de viajar se constituía em três etapas: a partida, o trajeto e a chegada. Com a aceleração geral do mundo contemporâneo, "a chegada generalizada dominou todas as partidas" (VIRILIO, 2000, p. 62). É o tempo que engole o espaço e o espaço que engole o tempo, em uma perda da própria experiência vivida. Ao lado da "ecologia verde", que denuncia a poluição da natureza, Virilio propõe uma "ecologia cinzenta":

A palavra "cinzento" significa que não há cor, é também uma referência à ontologia cinzenta de Hegel. Ao lado da poluição visível, bem material, bem concreta, há uma ecologia das distâncias. A poluição é também a poluição da grandeza natural pela velocidade. É por isso que eu falo de poluição dromosférica. A velocidade polui a extensão do mundo e as distâncias do mundo. Esta ecologia não é apreendida, porque ela não é visível mas mental. (VIRILIO, 2000, p. 63)

Nesse sentido, Virilio diz que corremos o risco de provocar o acidente dos acidentes: "o acidente do tempo". Catástrofe que vem acontecendo, aos poucos, quando a hipertrofia do presente vai dominando o 
passado e o futuro, na medida em que a partida vai eliminando o trajeto em nome da chegada.

Quando a velocidade aumenta, a duração diminui. Tal equação é, em síntese, o sentido que rege a aceleração dos objetos na sociedade de consumo. Fruto permitido e proibido do capitalismo, o objeto transformado em mercadoria foi se instituindo na constante diminuição da vida média. Nesse caso, o acelerado aumento da mortalidade dos artefatos corresponde ao insaciável incremento da natalidade. Objetos são criados em desespero contínuo, para alimentar o consumo, igualmente desesperado. Depois de comprado, o objeto não deve ter vida longa: desgasta-se logo ou logo fica "fora de moda". Nunca houve, em nenhuma sociedade, uma relação tão próxima entre a maternidade e cemitério.

Nessa perspectiva de estudar a biografia dos artefatos, não se pode desprezar, certamente, os aspectos quantitativos, as estatísticas que dão conta das várias trajetórias delimitadas no começo e no fim desses artefatos. Mesmo com algumas restrições, penso que se deve levar em consideração as sugestões de Abraham Moles em torno de uma “demografia dos objetos"(MOLES, 1973, p. 213).

Enfrentar a sociedade de consumo é, ou deveria ser, o pressuposto básico de qualquer atividade relacionada ao uso de objetos em aulas de história, pois a consciência histórica não trata do passado isolado e sim das várias tramas entre pretérito e presente, sem esquecer do campo de expectativas ligado ao futuro. O estatuto atual do objeto é, portanto, ponto de partida. Só assim torna-se viável, por exemplo, as chamadas "visitas educativas" aos museus ou quaisquer outros "lugares de memória".

Afinal, o conhecimento histórico se faz no presente e pelo presente que interpela o passado. A distância entre o que passou e o tempo atual não é o entrave ou o caminho a ser eliminado ou percorrido com a chamada "neutralidade científica". Como ressalta Gadamer, "o tempo não é um precipício que devamos transpor para recuperarmos o passado; é, na realidade, o solo que mantém o devir e onde o presente cria raízes" (GADAMER, 1998, p. 67).

Esse tempo, entre raízes e antenas, não é simplesmente a presença do presente, mas a presença das conexões que nós poderemos fazer entre passado e presente, passado e futuro. Aqui, por uma questão de recorte metodológico, vou me deter sobre a temporalidade dos objetos atuais, aqueles produzidos no calor da "sociedade de consumo". Com isso, defendo que se torna completamente indispensável, para a cons- 
trução da consciência histórica, a proposição de atividades pedagógicas com artefatos da contemporaneidade.

Uma proliferação incessante de objetos. Essa é, certamente, uma característica do mundo no qual vivemos. Além do aparecimento constante de certas novidades que rapidamente se tornam de uso mais ou menos comum, como o telefone celular, o videocassete ou o $\mathrm{CD}$, coisas já inventadas ganham rapidamente outras cores e formatos. Estamos, como diz Jean Baudrillard, no "tempo dos objetos". No passado, não muito distante, havia uma perenidade que hoje já não há: "Os objetos viam o nascimento e a morte de gerações humanas. Atualmente, são os homens que assistem ao início e ao fim dos objetos" (BAUDRILLARD, 1995, p. 15).

Quem nasceu nos anos 1970, não manuseou discos de cera, com uma música de cada lado. Para os adolescentes da década de 90, o disco de vinil apresentou-se como coisa fora de uso comum. E assim, vemos nascer e morrer objetos, com uma rapidez que assusta e excita, no desejo sempre renovado de consumir. O "tempo dos objetos" pressupõe a existência da "sociedade de consumo".

Nesse "tempo dos objetos", no qual nos encontramos, e nos perdemos, há uma infindável floresta de imagens sedutoras que, de modo estratégico, esconde sua malvadeza. Mas não se trata simplesmente de combatê-la, criando a polaridade entre a aceitação e a negação. Essa saída seria a mais fácil e, o que é pior, acabaria por contribuir, pela negação, para certo reforço em torno daquilo que se quer combater.

Como argumenta Baudrillard, a positivação e a negação do consumo constituem um grande mito do mundo contemporâneo, assim como acontecia com positividade de Deus e a negatividade do Diabo. Mas a situação piorou, porque ao redor do Demônio, ainda era possível a composição de heresias da magia negra. Hoje é diferente: "A nossa magia (...) é branca e a heresia é impossível na abundância. É a alvura profilática de uma sociedade saturada, de uma sociedade sem vertigem e sem história, sem outro mito além de si mesma". É por isso que Baudrillard encerra seu livro com uma provocação radical e profética: "Atingiremos as irrupções brutais e as desagregações súbitas que, de maneira tão imprevisível, mas certa, como em Maio de 1968, virão interromper esta missa branca" (BAUDRILLARD, 1995, p. 210).

Beatriz Sarlo indica que o consumidor da atualidade é um colecionador às avessas: "Em vez de colecionar objetos, coleciona atos de aquisição dos objetos". Coleciona, de modo excitante, "atos de compra e 
venda". Assim, há sempre uma ausência, falta de objetos que nunca é preenchida por novas aquisições. Depois de sair da vitrine, o objeto vai se desvalorizando e, mais cedo ou mais tarde, transforma-se em algo fora de uso, sem a sacralidade que o envolvia. Objetos efêmeros, que nos escapam: "Às vezes porque não podemos consegui-los, outras vezes porque já os conseguimos...”. Sorrateiramente, ergue-se um poder dos objetos, sedução de vida e morte: "A liberdade daqueles que os consomem surge da férrea necessidade do mercado de converter-nos em consumidores permanentes".

A identidade transitória afeta tanto os colecionadores às avessas quanto os menos favorecidos (...): ambos pensam que o objeto lhes dá (ou daria) algo de que precisam, não no nível da posse, mas no da identidade. Assim, os objetos nos significam: eles têm o poder de outorgar-nos alguns sentidos, e nós estamos dispostos a aceitá-los. (...) Os objetos são os nossos ícones, quando os outros ícones, que representavam alguma divindade, demonstram sua impotência simbólica; são os nossos ícones porque podem criar uma comunidade imaginária (cujo livro sagrado é o advertising, e cujo ritual é o shopping spree, e cujo templo é o shopping, sendo a moda o seu código civil). (SARLO, 2000, p. 27).

A "sociedade de consumo", que se reproduz em uma interminável rede de fome e morte, realiza-se, também, no desejo, na vontade insaciável do consumir, na produção incansável de objetos. Se o templo dos "colecionadores às avessas" é o shopping center, o altar de adoração é certamente a vitrine, lugar onde a sacralização do mercado mostra toda a sua carga de erotismo e cinismo. A velocidade ganha estatuto de lei canônica, que (des)regula o infinito gozo da liberdade de provar os sabores da novidade. O velocímetro vira relógio biológico, marcando os passos de uma liturgia profana e profanadora, mas em nome do sagrado e da sacralização.

\section{O PREÇO DO PRETÉRITO}

Fala-se que a aceleração do consumo e da urbanização cria terreno para mudanças, aumenta as tensões sociais e apressa, de modo mais organizado ou não, movimentos de contestação. Mesmo sabendo que desejo e masoquismo andam de mãos dadas, vale a pena apostar em um desgaste por meio da dor. É por isso que faz bem acreditar que, pelo menos em certa medida, Milton Santos tem razão ao avaliar que o consumo carrega um potencial autodestrutivo: "Convida-se ao consumo e os homens sofrem porque não podem consumir e daqui a pouco descobrirão que também sofrem porque consomem. O potencial de mudança tornase exponencial" (SANTOS, 2000, p. 67). 
Não é difícil perceber que alguns museus transformaram seus acervos em materiais de consumo visual, em conchavo com o "tempo dos objetos". Por outro lado, esse mesmo "tempo dos objetos" pode dar mais argumentos para o museu assumir nova abrangência: o próprio estudo das condições que possibilitam a "sociedade de consumo". No "tempo de objetos", o museu seria um núcleo educativo de insubstituível importância, centro de estudos sobre a historicidade dos objetos, instituição de pesquisa no qual o contemporâneo ganharia um status sem precedentes... Enfrentar, por meio dos objetos, os sentidos de passado e futuro que habitam o presente tornar-se-ia um desafio ético abrangente e, ao mesmo tempo, específico, uma via de posicionamento crítico em consonância com o desafio pedagógico do museu.

A questão é que, muitas vezes, a alternativa criada diante dos museus tradicionais, que glorificavam a história das classes dominantes, não foi a favor de um posicionamento reflexivo e sim em nome do espetáculo da "sociedade de consumo". Os museus, desse modo, embarcam na onda de consumo visual do patrimônio histórico, geralmente associado a um turismo predador. Daí, as chamadas "políticas culturais" ficam reféns do "mercado", para implementar a "indústria e o comércio dos bens simbólicos". E tudo é feito como "construção da cidadania”, porque gera "emprego e renda". Ora, o que muitas vezes acontece é que todo esse vocabulário que une cultura e economia vai minando aquilo que seria, dentro dessa mesma lógica do mercado, a "grande atração": o conjunto dinâmico das peculiaridades culturais. É claro que, na complexa rede de produtores, consumidores e intermediários, o casamento entre dinheiro e política cultural nas instituições públicas não é, em si mesmo, o demônio a ser afastado com a água benta do "intelectual engajado". O que se torna inadiável é sempre colocar em pauta os parâmetros da ética para o funcionamento do poder público e sua capacidade de intervenção, sobretudo a sua potência de assumir a condição de caixa de ressonância que é sensível à multiplicidade sutil e feérica das tessituras sociais. $\mathrm{O}$ que geralmente se vê nessa engrenagem é um esvaziamento do político em nome de estereótipos, daquilo que é postiço, artificial e oficial, e sobretudo daquilo que é passível de se transformar em "material de consumo". Afinal, se estamos falando de políticas públicas, é fugir da ética pública submeter-se aos padrões do mercado.

O caráter educativo do museu não pode fugir do posicionamento crítico diante da "sociedade de consumo". A questão crucial é saber que, ao se transformar em "Shopping Center Cultural", o museu e as 
políticas de preservação do patrimônio cultural perdem a força educativa, transformam-se em mais um bem de consumo rápido, conforme as exigências do mercado globalizado.

O culto do patrimônio leva progressivamente a se fazer museu de qualquer coisa e qualquer prática antiga, de ontem e hoje. O que aponta para uma vulgarização, já quase uma depreciação pela inflação, dos valores do passado. Os críticos da museumania o constatam, e denunciam as ilusões do patrimonialismo ubiqüitário. Os mais radicais vêem nisto uma substituição da memória viva enfraquecida pelas memórias artificiais, ou, pior, um sinal da derrota de uma memória arrastada para sua perda nas turbulências atuais. A herança do passado importaria então menos por seu conteúdo - o que ensina, significa e valoriza - do que por aquilo que leva à sua aparência e ao seu consumo. Os caminhos embaralhados da memória só levariam assim às simulações espetaculares em que as obras se dissolvem nas aparências, nas relações inconstantes regidas pelas modas. (BALANDIER, 1999, p. 54).

A política do exibir passa a se orientar em novos padrões de visibilidade, formas de olhar que vão se configurando no ritmo acelerado da sociedade que, para vender, inventa toda sorte de estratégias para aumentar o desejo de consumo. É por isso que, em muitos museus, emerge "um espaço híbrido, entre a diversão pública e uma loja de departamento", como diz Andreas Huyssen (HUYSSEN, 1994, p. 36).

É claro que o desastre de tal hibridismo não reside na "diversão pública", mas na semelhança do museu com a "loja de departamento". O museu educativo não vem para confirmar o existente, sua tarefa consiste em refletir sobre o que somos e o que podemos ser. As vitrines do museu não podem ficar submetidas aos padrões de visibilidade das vitrines do comércio. A sedução do museu educativo não está na ordem do consumo capitalista, que promove o "culto ao patrimônio", e sim na aventura de criar condições para o pensamento livre e, por isso mesmo, comprometido com alternativas diante da lógica perversa do mercado.

Por outro lado, é preciso ver o sentido em que essa espécie de veneração fetichista do passado funciona em nosso país. Se Georges Balandier fala em "culto ao patrimônio", é preciso saber onde e como isso acontece. Certamente sua reflexão se refere sobretudo à Europa e aos Estados Unidos. No Brasil, há outras cores para esse desenho conceitual. Desse modo, não adianta simplesmente importar as teorias do além-mar que discutem o interesse que as classes dominantes têm no sentido de conservar e glorificar suas memórias. Basta lembrar que, em nossas cidades, a regra é o pouco cuidado com o patrimônio edificado e um fascínio quase incontrolável diante do novo, uma vontade compulsiva de 
"ser moderno". Isso quer dizer que, ao invés de restaurar, a opção mais comum é a destruição. Uma dificuldade a mais, pois nem mesmo o tradicionalismo de conservação da memória dominante conseguiu grande êxito.

Afinal, como interpretar o desprezo pelo passado? Como estudar a falta de afetividade diante do chamado "patrimônio histórico"? Como ficam as políticas públicas de preservação? O que colocar no lugar daquela política autoritária e excludente que caracterizou, por muito tempo, as ações do IPHAN? Bem, uma coisa é certa: o desafio não foi enfrentado de modo mais incisivo porque o que ainda predomina é a urgência do salvamento, espremida pela falta de recursos e mão-de-obra especializada.

Seria coerente supor que as classes dominantes fariam investimentos para conservar suas memórias. É assim que poderíamos concluir a partir das teorias sobre o poder da memória. Mas, nem tanto. Se na Europa tal investimento é quase regra, aqui no Brasil é exceção. A teoria da preservação da memória oficial, quando pensada aqui, ganha outra tonalidade.

A coisa está mudando, entretanto a mudança não é a favor da preservação de documentos históricos, através dos quais pensássemos sobre nossa própria história. O que predomina é o patrimônio como "bem de consumo". É por isso que a intervenção no Pelourinho, em Salvador, por muitos chamada de "revitalização", transformou a densidade histórica do lugar em passeio de turista. Aquilo que era marca do tempo, vestígio de muitos pretéritos, tornou-se um shopping center no estilo colonial, com um florescente comércio que fez dos prédios cenários de venda, com fachadas recompostas, repintadas e tudo destruído por dentro, para atender à necessidade da colocação de vitrines e balcões.

A arapuca não está propriamente no turismo em geral, mas em um tipo de turismo que tem se desenvolvido na atualidade, transformando traços culturais em estereótipos que vão agitar o volume de vendas: venda de produtos, imagens e paisagens. Ora, quando as políticas públicas na área da cultura ficam reféns desse turismo da sociedade de consumo, o que emerge é o "produto típico", que já se distanciou das peculiaridades culturais para se transformar em produto vendável. É nessa perspectiva que os programas de restauração, como aconteceram no Pelourinho, elegem o objetivo de incentivar e seduzir "um consumidor que deve usar o bem cultural como uma atraente mercadoria ou como apoio ao consumo de outras mercadorias" (MOT'TA, 2000, p. 270). 
"Permitiremos a transformação do museu em um lugar reservado ao público dos hotéis e restaurantes?" Pergunta colocada por Hugues de Varine no final dos anos 1960 e que, no passar do tempo, com o crescimento da indústria do turismo predador, foi aprofundando o sentido de questão fundamental para quem se preocupa com a relação entre patrimônio e educação" (VARINE, 1992, p. 54).

É claro que o problema não está no turismo e sim no turismo consumista, que opera uma inversão de valores. Dentro da proposta pedagógica aqui defendida, não há nenhum exagero em falar que o turismo é uma das atividades mais educativas, no sentido de gerar o juízo crítico sobre a nossa história. Conhecer os outros, que vivem perto ou longe, é um ponto fulcral na compreensão daquilo que somos. Deslocar-se no espaço, para percorrer outras dinâmicas culturais, fazendo analogias e apreciando distinções, é uma experiência necessária e insubstituível. Mas não é esse o sentido do turismo dominante...

O que vem acontecendo nas chamadas "políticas de defesa do patrimônio" é o investimento público que busca legitimidade no ato de promover o "desenvolvimento turístico", como é o caso de Salvador. Então, aquilo que deveria ser a cultura vivida, patrimônio vivido em suas tensões e multiplicidades, passa a fazer parte do cardápio artificial, com produtos expostos em museus, centros culturais ou áreas de preservação, para consumo visual, ou em lojas para quem puder comprar o tão falado "produto típico". Enfim, a historicidade é empacotada, asfixiada, e depois vendida. Mas, se o capitalismo torna-se mais avançado, mais planejado e apto para manipular as palavras, tudo isso é entrelaçado com aquilo que se convencionou chamar de "programas sociais". E, bem ou mal, o quiproquó vai funcionando, em nome de coisas aparentemente inatacáveis, como "geração de emprego e renda", resgate da cultura popular, da identidade cultural e até mesmo em nome da educação patrimonial...

Ora, a proposta aqui defendida para as políticas patrimoniais e, especialmente, para as políticas museológicas, não se ancora na preservação de uma suposta "identidade cultural" ou do "resgate do nosso passado", e sim no direito à diversidade histórica, o direito à multiplicidade das memórias como pressuposto básico para a construção de um potencial crítico diante da nossa própria historicidade. Assim, a preservação tem o intuito de dar a todos nós o direito de saborear a diferença, de perscrutar as marcas de outros tempos, criando em nós a consciência de que somos seres historicamente constituídos. Se vamos apagando a materialidade do pretérito, que está, por exemplo, na própria configuração urbana, 
vamos esvaziando o jogo do tempo, aniquilando o processo educativo de entrar em contato com o tanto de experiência vivida que pode ser encontrada no mundo dos objetos.

Enfim, como não poderia deixar de ser, há nisso tudo uma questão de fundo político na relação que se faz entre memória e preservação (ou estudo) da memória, entre cultura e administração das instituições públicas chamadas "culturais", como museus, arquivos, teatros, secretarias de cultura, etc. E, contrariando o clichê, não se trata somente de descobrir as "raízes culturais". O mais importante é dialogar com o que já foi feito, sabendo por quem foi feito, para quem e contra quem foi feito. Tratar a cultura em sua constituição conflituosa, dialogar com o passado, não para sentir saudade ou tentar salvá-lo do esquecimento, mas para interpretá-lo como fonte de conhecimento a respeito das nossas idas e vindas nos mapas da temporalidade. Se vamos apagando as marcas do pretérito, perdemos o potencial educativo de experimentar as diferenças temporais, de sentir a estética do tempo como forma de entender o que éramos, o que somos e o que poderemos ser.

\section{0 TEMPO PLASTIFICADO}

Para trabalhar com objetos da sociedade de consumo no ensino de história, é preciso considerar, antes de tudo, que tais objetos devem ser tratados como documentos históricos. E os documentos históricos só fertilizam a reflexão crítica a partir de problemáticas historicamente fundamentadas. Os tempos de duração dos artefatos contemporâneos podem ser, por exemplo, um campo fértil para a composição de problemas históricos nas aulas de história, em interação com outras áreas, como a biologia, a química e a física. O inegociável, na chamada interdisciplinaridade, é simples: as disciplinas não podem desaparecer.

Cito um caso concreto para deixar mais clara a posição, aqui defendida, a respeito dessa perspectiva interdisciplinar. Trata-se do livro Plástico: bem supérfluo ou mal necessário?. A introdução é a seguinte:

Há séculos o homem retira da natureza materiais úteis ao seu conforto. Madeira, borracha, lã, seda, algodão, couro e peles de animais - empregados na fabricação de artigos do dia-a-dia, tais como móveis, pneus, roupas, calçados e tapetes - são apenas alguns exemplos.

Em certos casos, a evolução da tecnologia possibilitou que materiais fossem processados e, após passarem por modificações adequadas, fornecessem produtos com importantes aplicações.

É o caso do papel, cuja fabricação envolve uma série de transformações químicas sofridas pela polpa da madeira. Ou de metais como ferro e alumínio, que, por intermédio de reações químicas apropriadas, são obtidas a partir de, 
respectivamente, hematita e bauxita, minérios encontrados no subsolo.

Dentre os muitos materiais criados com avanço da tecnologia estão os plásticos.

Elimine do seu cotidiano o colchão, o travesseiro, a escova de dentes, os carpetes e os tapetes, os cobertores de fibra acrílica, as roupas de náilon e de poliéster, os guarda-chuvas e guarda-sóis, o baquelite presente em placas de circuitos eletrônicos de televisão e rádio, o teflon das frigideiras antiaderentes e o polietileno das canetas, das lapiseiras, dos sacos de lixo e das sacolas de compra, apenas para citar alguns poucos exemplos. Como seria sua vida sem esses objetos feitos de plásticos?

Imagine um automóvel. Como ele seria se os plásticos não existissem? Painel, pára-choques, estofamentos, tapetes, lanternas, acabamento das laterais e do teto, pneus e muitos outros itens deixariam de ser como os conhecemos.

Tinta, borracha e espumas sintéticas são também substâncias pertencentes ao grupo dos plásticos. Sem dúvida, dificilmente desfrutaríamos do mesmo conforto se eles não estivessem presentes em nosso dia-a-dia.

Podemos dizer que a humanidade, que já vivenciou as idades da Pedra Lascada, da Pedra Polida e dos Metais, encontra-se atualmente na Era dos Plásticos.

Leves e resistentes, práticos e versáteis, duráveis e relativamente baratos, eles são uma das expressões máximas da idéia da tecnologia a serviço do homem. Contudo, em virtude de sua não-degradabilidade e também da redução progressiva dos estoques naturais de matérias-primas, eles podem representar uma série ameaça ao meio ambiente.

Vale a pena ter o conforto proporcionado pelos plásticos, mesmo sabendo que, num futuro próximo, os terrenos sanitários poderão estar abarrotados de montanhas de lixo plástico, que demorarão décadas para desaparecer? Compensa viver com a poluição proveniente das indústrias que os produzem? É sensato utilizar o petróleo, fonte de combustível e de matéria-prima, para fabricar plásticos, cujo destino final é o lixão municipal?

Mas, por sua vez, seria uma decisão inteligente proibir a fabricação desse tipo de material e viver sem o conforto que ele traz? Seria justo suspender o uso de plásticos como, por exemplo, o teflon, empregado em próteses ósseas, marcapassos e dentaduras? Enfim, haveria um meio-termo conciliador para todas essas e tantas outras questões polêmicas relativas aos plásticos?

Mocinho ou bandido? Bem supérfluo ou mal necessário? Este livro não tem a pretensão (ou, até por que não dizer, o autoritarismo) de esboçar uma resposta acabada e definitiva a essa indagação. Sua proposta consiste, ao contrário, em fornecer um mínimo de informação científica e tecnológica sobre os plásticos, suas propriedades e aplicações, vantagens e desvantagens.

Então, após estar munido dessas informações - e, espera-se, tanto vacinado contra as maravilhosas colorações publicitárias que endeusam os plásticos, quanto prevenido contra "ecologismos catastróficos" e "chutes" baseados no senso comum e nas informações veiculadas pela mídia (nem sempre corretas e confiáveis nos seus aspectos científicos) -, cabe ao leitor posicionar-se, como pessoa e cidadão, diante dessa controvertida e atual discussão.

Faz, portanto, parte da proposta desta obra proporcionar subsídios para que o leitor possa entender por que há tanta polêmica no que diz respeito aos 
plásticos, à necessidade de seu reaproveitamento através da reciclagem e à sua degradação natural por intermédio de uma produção que pense nisso previamente.

Finalizando a introdução, gostaria de esclarecer que, embora este livro seja destinado a pessoas que já se iniciaram no estudo de Química do Ensino Médio, acredito que um leigo também possa tirar algum proveito do conteúdo aqui exposto. Basta não dar às formulas e nomes químicos uma importância maior do que eles têm. (CANTO, 2004, p. 09)

É um texto aparentemente interdisciplinar, na medida em que parece promover a construção do conhecimento histórico. Aparentemente porque não se deve confundir a história problema com a história narrativa. Em poucas palavras, mais informações sobre o passado e o presente não é a mesma coisa de mais consciência histórica. Até existe, nesse livro, um capítulo intitulado "Um pouco de história dos plásticos", mas aí é que se percebe, de modo mais dramático, a falta de uma fundamentação histórica.

Não cabe, aqui no curto espaço deste artigo, uma análise mais detalhada sobre isso, até porque esse livro faz parte de um variado conjunto de publicações pretensamente didáticas que, a rigor, estão mais próximas de uma certa literatura de auto-ajuda para quem acha que o saber se confunde com armazenamento de informações. Vou apenas identificar uma carência que deixa ainda mais anêmico o sentido crítico que o referido autor deseja ter: não há discussões sobre as inúmeras conexões entre o desenvolvimento do plástico e a (re)produção das desigualdades sociais na exploração capitalista. A evolução da técnica fica solta no ar, como se bastasse citar uma seqüência de inventores e suas invenções ou um inventário de problemas técnicos e soluções igualmente tecnológicas.

A ecologia até aparece, mas igualmente solta, como se a questão fosse apenas defender ou acusar o plástico, como se houvesse neutralidade científica diante da sociedade, da economia, da política, dos objetos... Tudo é resumido na simplificação do título: "Plástico: bem supérfluo ou mal necessário?”.

Não há dúvidas, por outro lado, de que certas informações trazidas nesse livro podem ser fundamentais, mas na medida em que forem inseridas em problematizações históricas, prontas para gerar reflexões sobre a nossa condição de criadores e criaturas do tempo.

Conhecer o passado de modo crítico significa, antes de tudo, viver o tempo presente como mudança, como algo que não era, que está 
sendo e que pode ser diferente. Mostrando relações historicamente fundamentadas entre objetos atuais e de outros tempos, o museu e a sala de aula ganham substâncias educativas, pois há relações entre o que passou, o que está passando e o que pode passar.

No cotidiano, usamos uma infinidade de objetos: desde a televisão até uma roupa. Por outro lado, pouco pensamos sobre os objetos que nos cercam. Se pouco refletimos sobre nossos próprios objetos, a nossa percepção de objetos expostos no museu será também de reduzida abrangência. Sem o ato de pensar sobre o presente vivido, não há meios de construir conhecimento sobre o passado. E o próprio conhecimento do presente já pressupõe referências ao pretérito. É por isso que qualquer museu histórico pode (e deve) ter, em seu acervo, artefatos do mundo contemporâneo.

Se aprendemos a ler palavras, é preciso exercitar o ato de ler objetos, de observar a história que há na materialidade das coisas. Além de interpretar a história através dos livros, é plausível estudá-la por meio de objetos. Foi pensando nisso que, em 2004, publiquei o livro $A$ danação do objeto: o museu no ensino de bistória (RAMOS, 2004).

Perguntar-se sobre nossas roupas comparando-as com as vestimentas da década de 1950 ou da aristocracia francesa do século XVIII é, por exemplo, uma das questões que podem desencadear processos de sensibilização para a historicidade dos objetos com os quais lidamos no diaa-dia. Uma outra questão poderia vislumbrar a relação entre o relógio que está no braço dos alunos, ou no pátio, e a noção de tempo necessária à chamada "Revolução Industrial". Ou a relação desse mesmo relógio com a "sociedade de consumo". Pode-se questionar a ligação do relógio com a destruição da natureza, a busca de lucros que insidiosamente proclama que "tempo é dinheiro", as diferenças entre o tempo dos "índios" que não usavam relógios e o tempo do mundo capitalista...

No museu ou na sala de aula, um copo descartável pode ser tomado como fragmento do tempo monetário, no qual tudo deve durar pouco, pois o ideal é sempre acelerar os índices de consumo. Mais coisas consumidas em menor quantidade de tempo: tempo marcado pela matemática e pouco marcante nas afetividades da memória, tudo em nome de um presente artificialmente eternizado.

O melhor exemplo que eu conheço de trabalho com tais artefatos foi dado por Ulpiano Bezerra de Meneses:

Um museu de cidade, por exemplo, pode contar com uma coleção de relógios de rua. E pode ampliar tipologicamente tal coleção e também expô-la tipologicamente, em paralelo a várias outras classes de objetos, cada uma em seu 
segmento taxonômico. Pouco conhecimento se terá da cidade, salvo numa escala pontual e limitada. Sequer ficariam claras as funções desse tipo de monumento urbano. No entanto, caso se parta de um problema (que própria coleção de relógios pode sugerir), como a do tempo enquanto forma de controle social no espaço urbano, já se pode montar uma estratégia e mobilizar outras coleções existentes ou definir uma política de coleta. Assim, a partir do relógio de rua, como referência que projetava no espaço urbano as significações do tempo enquanto fator de organização e convergência, numa sociedade em processo rápido de fragmentação, buscar-se-iam relações com outras formas de controle social por meio dos objetos pertinentes. Como, por exemplo, a domesticação do tempo natural pelas exigências da produção, que nossa sociedade impõe. A produção requer continuidade, mas o tempo natural apresenta rupturas como a alternância dia/noite. Daí ser adequado incorporar à exposição coleções de equipamentos de iluminação (doméstica, industrial, de rua), capazes de permitir o entendimento deste domínio sobre o tempo. Outra relação poderia ser com o domínio da duração das coisas, da vida útil dos objetos reduzidos a mercadoria, a fim de que elas circulem mais rapidamente (é, portanto, a mesma matriz). Assim, a exposição contaria também com uma coleção de objetos descartáveis, como embalagens, copos, por exemplo, ou outros objetos marcados pelo efêmero ou pela obsolescência programada. Poderia parecer uma exposição compósita, eclética. De fato, mas nisso mesmo ela remete às múltiplas malhas da interação social, sem a qual escaparia o sentido histórico dos diversos tipos de objetos exibidos. (BEZERRA DE MENEZES, 1994, p. 32).

Aqui, a base é a problemática histórica diante dos objetos, em diálogo político com as teorias sobre a sociedade de consumo. É claro que, a partir dessa preciosa sugestão, pode-se abrir um amplo território de possibilidades educativas. Imagino grandes exposições, juntando os mais variados objetos descartáveis com os mais variados relógios, a partir de recortes que vão depender do enfoque que se deseja. Por outro lado, penso em pequenas exposições de estudantes do ensino fundamental ou médio, na sala da escola, com propostas que podem relacionar história e biologia, por exemplo.

Seria interessante levar certos objetos de plástico para aulas sobre temas clássicos, como industrialização, urbanização ou globalização. É plenamente viável propor que, além da voz, os professores utilizem objetos, não importando o tema, porque o que dá a qualidade da construção da consciência histórica é o problema historicamente fundamentado.

Pode-se pensar, por exemplo, como há relações entre o desenvolvimento do capitalismo e a redução do tempo dos objetos, inclusive com destaque para a atual proliferação de relógios de plástico e o crescente desaparecimento de oficinas de consertar relógios. 
E a relação dos relógios com as propagandas? Refiro-me não somente a propagandas para vender relógios, que podem ser facilmente encontradas em jornais e revistas de todo século XX e que apresentam um infindável cardápio de indícios sobre os usos dos ponteiros, passando por questões de gênero, classe social, distinções entre público e privado, simbologias do poder.

Reporto-me, também, às atuais propagandas nos relógios públicos e privados. Atrás dos ponteiros, é comum a colocação de informes publicitários. Trata-se de um recurso que extrapola a propagação do consumo, entrando, sem pudores, na propaganda da fé. Afinal, não é difícil encontrar no comércio de eletrodomésticos a existência de relógios de plástico com a figura de um santo atrás dos ponteiros. E, nesse caso, nem é preciso dizer que há sempre um furo no rosto da imagem, quase sempre no nariz, evidenciando que a lógica de funcionamento dos objetos nas sociedades sempre foge de regras congeladas.

Outro desdobramento possível para o exercício é comparar o tempo mecânico do relógio com a noção de tempo de outras culturas. Se observarmos a temporalidade vivida pelos chamados "índios", veremos que há uma considerável distância entre o que somos e o que eles são, dando a nós a possibilidade de pensar sobre o quanto há de glória e malvadeza em nossa própria experiência de contar as horas. Somos cativos do tempo? Como esse sentido de prisão foi se tornando possível? Como o relógio transformou-se em objeto normal e necessário?

Vale ainda breve menção ao emprego de certos objetos (como o próprio copo plástico) para entabular diálogos interdisciplinares, a exemplo dos relacionados à educação ambiental. Um objeto descartável tem seu valor de uso aviltado, reduzido, depreciado pela rapidez de seu consumo/destruição, mas sua matéria-prima cobra e dá a ver o alto custo social e natural da produção fabril massificada: o plástico, que, em um momento fugaz, era objeto e, logo depois, virou lixo, requer algumas centenas de anos para se decompor no meio ambiente, pois não é biodegradável. Isso, obviamente, implica discussões sobre o estatuto do objeto na sociedade de consumo.

Nesse sentido, é plausível discutir a criação de "Museus do Consumo", que seriam, em certo sentido, a mesma coisa de "Memoriais do Lixo". Afinal, a sociedade de consumo, na qual vivemos, se faz na medida em que produz uma sociedade do lixo. Além de ser "meio de vida" para milhares de moradores das periferias, o lixo expõe e esconde uma multiplicidade de vivências com os objetos. Objetos que são restos 
do consumo, ou melhor, objetos que já foram definitivamente consumidos dão uma reviravolta e começam a despertar uma série de consumos que, em certo sentido, são inusitados, de uma criatividade anônima que se compõe nas táticas de sobrevivência. (RAMOS, 2004).

Nas casas da periferia, em sua própria constituição ou em objetos de uso doméstico, está a infinita presença dos materiais já gastos pela sociedade de consumo: plásticos, vidros, latas, papéis, papelões, borrachas, ferros, alumínio. Garrafas de plástico ou vidro transmutam-se em recipientes utilitários ou adornos; latas viram copos ou a parede da casa; coisas de plásticos geram flores de plástico; tudo é recortado, refeito, reposto, repintado, tudo é (re)formado, em uma dinâmica permanente e provisória, de vida e morte, de esquecimento e memória, profunda e à flor da pele, imanente e transcendente.

A sociedade de consumo é a sociedade do descartável somente para uma parcela da sociedade: os que têm dinheiro para consumir. Para a grande maioria, o descartável é a possibilidade de restituir a vida dos objetos, dando-lhes um pequeno valor monetário ou novas utilidades. $\mathrm{O}$ objeto finado transfigura-se em objeto ressuscitado.

Mas tudo continua transitório, de pouca durabilidade, e o lixo utilizado com pouco tempo volta ao lixo inútil, mas que talvez ainda possa ser útil em alguma indústria de reciclagem.

$\mathrm{Na}$ sociedade cheia de objetos, novos ou com novos formatos, há um imenso vazio. Temos, então, um paradoxo inevitável: a proliferação dos objetos cria, ao mesmo tempo, uma deliberada perda de durabilidade, uma presença que se realiza na ausência programada. Os objetos já nascem para morrer rapidamente, em nome do "avanço tecnológico", do "novo modelo", do "conforto", da "beleza" e da "saúde" dos "usuários". O obituário das invenções cresce vertiginosamente. $\mathrm{Na}$ medida em que tem íntima relação com as mazelas e glórias das subjetividades contemporâneas, a curta duração dos objetos deve necessariamente ocupar um lugar de destaque nas reflexões sobre os feitos e as faltas dos museus (e das aulas) de história.

E não se trata apenas de desenvolver trabalhos com temáticas mais específicas, como "museu do telefone", "museu do brinquedo" ou "memorial do lixo". Ao pôr em cena a necessidade de coletar, conservar e expor objetos da atualidade, os museus não podem fugir do debate sobre os sentidos dos objetos na "sociedade de consumo", levando em consideração a grande complexidade que reside no próprio desenvolvimento do capitalismo. 
Com atividades vinculadas à "historicidade dos objetos" na própria sala de aula, o professor incita a percepção dos alunos e aí eles terão o direito de saborear, com mais intensidade, as propostas de reflexão oferecidas pelo museu. Desse modo, não se trata mais de "visitar o passado", e sim animar estudos sobre o tempo pretérito, em relação com o que é vivido no presente. Com a excitação para a aventura de conhecer através de perguntas sobre objetos, abre-se espaço para a percepção mais ampla diante da exposição museológica. Mais que isso: alarga-se o juízo crítico sobre o mundo que nos rodeia.

Estudar a história não significa saber o que aconteceu e sim ampliar o conhecimento sobre a nossa própria historicidade. Saber que o ser humano é um sendo, campo de possibilidades historicamente condicionado e abertura para mudanças. É por isso que Paulo Freire argumenta que a pedagogia do diálogo está enraizada na "situacionalidade" do ser no mundo: "Os homens são porque estão em situação". O ato educativo alarga o ser humano na medida em que se considera o ser um estar - prática cotidiana de pensar e atuar criticamente sobre a situação em que se constitui o estar no mundo e com o mundo (FREIRE, 1987, p. 101).

\section{REFERÊNCIAS}

BALANDIER, Georges. O Dédalo - para finalizar o século XX. Rio de Janeiro: Bertrand Brasil, 1999.

BAUDRILLARD, Jean. O sistema dos objetos. São Paulo: Perspectiva, 1993.

BAUDRILLARD, Jean. A sociedade de consumo. Lisboa: Edições 70, 1995.

BEZERRA DE MENEZES, Ulpiano. Do teatro da memória ao laboratório da História: a exposição museológica e o conhecimento histórico. Anais do Museu Paulista, São Paulo, Nova Série, v. 2, 1994.

CANTO, Eduardo Leite do. Plástico; Bem supérfluo ou mal necessário? 2 ed. São Paulo: Moderna, 2004.

FREIRE, Paulo. Pedagogia do oprimido. Rio de Janeiro: Paz e Terra, 1987.

GADAMER, Hans-Georg. O problema da consciência histórica. Rio de Janeiro: Fundação Getúlio Vargas, 1998.

MOLES, Abraham. Rumos de uma cultura tecnológica. São Paulo: Perspectiva, 1973.

MOTTA, Lia. A apropriação do patrimônio urbano: do estético-estilístico nacional ao consumo visual global. In: ARANTES, Antônio Augusto (Org.). O espaço da diferença. Campinas: Papirus, 2000.

HUYSSEN, Andreas. Escapando da amnésia: o museu como cultura de massa. Revista do Patrimônio Histórico e Artístico Nacional, Rio de Janeiro, n. 23, 1994.

RAMOS, Francisco Régis Lopes. A danação do objeto: o museu no ensino de história. Chapecó: Argos, 2004.

SARLO, Beatriz. Cenas da vida pós-moderna. Rio de Janeiro: Ed. UFRJ, 2000.

SANTOS, Milton. Território e sociedade - entrevista com Milton Santos. São Paulo: Perseu 
Abramo, 2000.

VARINE, Hugues de. Le musée au service de l'homme et du développement. (1969) In: Desvallées, André. Vagues: une anthologie de la nouvelle museologie. Paris: Éditions W.M.N.E.S., 1992.

VIRILIO, Paul. Cibermundo: a política do pior. Lisboa: Editorial Teorema, 2000.

Recebido: $17 / 04 / 08$

Aprovado: 02/05/08

Contato:

Rua General Silva Junior, 800, apto. 802

Fortaleza - CE

BRASIL

CEP: 60411-000

E-mail: regisufc@hotmail.com 